\title{
3
}

\section{O PODER JUDICIÁRIO ENTRE EFICÁCIA E EFICIÊNCIA}

\section{The judiciary between effectiveness and efficiency}

\section{Fernanda Estevão Picorelli}

Mestre em Direito Público e Evolução Social pela UNESA; especialista em Administração do Poder Judiciário (MBA) pela FGV/Rio; especialista em Direito Civil pela UNESA; Analista Judiciário da Justiça Federal do Rio de Janeiro desde 1993, tendo exercido diversas funções de Direção, supervisão e assessoramento. E-mail: fernanda.picorelli@globo.com.

RECEBIDO EM: 01.08.2013

Aprovado EM: 24.08.2013

\section{RESUMO}

A jurisdição, tradicionalmente conectada à prestação outorgada à sociedade pelo braço Judiciário do Estado, vem exigindo profunda atualização em seu significado, dado que sua acepção corrente, atrelada à singela aplicação da lei aos fatos da lide, hoje está defasada e é insuficiente, cedendo espaço à concepção de que o direito há de se ter como realizado quando um conflito é prevenido ou solucionado de modo eficaz e eficiente. Este desiderato pode ser alcançado por meio da Justiça oficial, desde que haja uma mudança de paradigmas e seja adotada uma política judiciária que seja fulcrada na gestão da qualidade. Colima-se que esta traga como signos positivos não só a aplicação das modernas técnicas de gestão, mas também a abertura a outros ramos do saber, a participação de novos atores sociais no processo de formulação das escolhas públicas, por meio da governança pública, e o contínuo fomento à cultura da adoção dos meios complementares de acesso à justiça.

Palavras-chave: Política judiciária. Gestão da qualidade. Governança.

\section{Abstract}

Jurisdiction, traditionally connected to the provision granted to society by the Judiciary arm of the State, has been demanding a deep update on its meaning, given that its current formulation, related to the simple application of the law to the facts of the dispute, is now outdated and is insufficient, giving way to the concep- 
tion that the right is to be considered as carried out when a conflict is prevented or solved in an effective and efficient way. This goal can be reached through the official Justice, as long as there is a paradigm shift and the adoption of a judiciary policy that is based on quality management. It is expected that this brings as positive signs not only the application of modern managerial techniques, but also the opening to other branches of knowledge, the participation of new social actors in the process of choosing public policies, by means of public governance, and the continuous promotion of the culture in which complementary means of access to justice are adopted.

KeyWORDS: Judiciary Policy. Quality MANAGEMEnt. Governance.

\section{INTRODUÇÃo}

A chamada crise do Judiciário, consubstanciada na defasagem entre as expectativas sociais e o que efetivamente se consegue realizar em termos de prestação jurisdicional, deflagra severas críticas e manifestações para que aquele Poder abandone o imobilismo e hermetismo corporativo, redescubra sua missão pública e repense sua forma de atuação na sociedade. Afinal, se o titular do poder é o povo e o Estado organizado é mero gestor da coisa pública, a finalidade de obter o bem-estar social a que aquele ente se destina deve ser efetivamente cumprida, sob pena de esvaziar-se a própria razão de ser do Estado.

Sob essa perspectiva, este estudo apresenta, a partir do intercâmbio com outras ciências e da ruptura de vetustos paradigmas, um conjunto de soluções para alicerçar uma política judiciária que venha a maximizar a efetividade dos direitos fundamentais e, ipso facto, a legitimidade do Judiciário, saindo de cena a visão unívoca que se tem dado à ampliação de sua estrutura e de reiteradas alterações legislativas para resolver as dificuldades por ele enfrentadas. Não se trata de apresentar certezas, mas de operar com outros ramos do conhecimento para que se iluminem caminhos que apontem para uma prática administrativa mais consentânea com os compromissos finalísticos do Judiciário, a partir da participação de novos atores sociais e da expertise necessária ao enriquecimento do complexo processo de formulação das escolhas públicas, por meio da governança, e de outras necessárias ações políticas continuadas e eficientes que reduzam a avassaladora demanda que é dirigida àquele ente estatal. Como conseqüência, espera-se que a democratização do acesso à justiça possa ser vivida como verdadeira arena de aquisição de direitos e de animação para uma cultura cívica.

Na experiência brasileira, a formação do Estado foi eminentemente autoritária.

Em Portugal e, como consequência, também no Brasil, houve grande atraso na chegada do Estado liberal. Permaneceram, assim, indefinida e indelevelmente, 
os traços do patrimonialismo, para o que contribuiu a conservação do domínio territorial do rei, da Igreja e da nobreza. O colonialismo português que, como o espanhol, foi produto de uma monarquia absolutista, legou-nos o ranço das relações políticas, econômicas e sociais de base patrimonialista, que predispõe à burocracia, ao paternalismo, à corrupção e à ineficiência.

O entrelaçamento desses dois sistemas de organização - burocracia e relações pessoais - projetaria uma distorção que marcaria profundamente o desenvolvimento de nossa cultura jurídico-institucional e político-administrativa, caracterizada pela coexistência antagônica e conflitante de procedimentos racionais (burocracia) com formas tradicionais (patrimonialismo). Ambas expressões foram utilizadas em termos sociológicos por Max Weber para configurar o desenvolvimento de certa prática de organização política pré-moderna e, também, designar fenômenos distintos, movidos por "princípios reguladores opostos" (WOLKMER, 2010, p. 87). Esclareça-se: a burocracia como foi entendida por Weber, consistente no método de administração do Estado, imparcial, eficiente e hierarquizado, deveria ter como objetivo a reiteração da dominação racional-legal e não patrimonialista ou carismática. Ao mesmo tempo em que foi estabelecido um encadeamento de regras normativas para reforçar o poder pelo povo, passou a existir um sistema para manter uma classe dominante no poder (a classe burocrática). Trata-se de contradição das formas de dominação, que fez eclodir, de um lado, a burocracia, como dominação racional-legal; de outro, a estamentária, como dominação tradicional patrimonialista. Apesar de epistemologicamente contraditório, o trinômio burocracia-patrimonialismo-democracia, é uma realidade no território brasileiro, que, contudo, vem sendo contemporaneamente guerreada por meio de ações políticas que objetivam anular seus indesejáveis efeitos ( $\mathrm{vg}$. Resolução $\mathrm{n}^{\circ} 07 / 2005$, do CNJ, por meio da qual foi combatido o costume contra constitutionis chamado nepotismo no Poder Judiciário).

Não resta dúvida de que o nascedouro da produção jurídica no Brasil e a forma como os tribunais vieram a institucionalizar-se estão profundamente amarrados a um passado econômico e sócio-político colonial. Isso permite compreender que o direito oficial nem sempre representou o genuíno espaço de cidadania, de participação e das garantias legais para grande parte da população. A triste verdade, como assinala BARROSO (2006, p. 11), é que o Brasil jamais se libertou de sua herança patrimonialista. Tem vivido assim, por décadas a fio, sob o signo da má definição do público e do privado. Pior: sob a atávica apropriação do Estado e do espaço público pelo interesse privado dos segmentos sociais dominantes. Do descobrimento ao início do terceiro milênio, uma história feita de opressão, insensibilidade e miséria. A Constituição de 1824, primeiro esforço de institucionalização do novo país independente, pretendeu iniciar, apesar das vicissitudes que levaram à sua outorga, um Estado de direito, quiçá um protótipo de Estado liberal. Mas foi apenas o primeiro capítulo de uma instabilidade cíclica que marcou a experiência republicana brasileira, jamais permitindo a consolidação do modo liberal e, tampouco, de um Estado 
verdadeiramente social. De visível mesmo, a existência paralela e onipresente de um Estado corporativo, cartorial, financiador dos interesses da burguesia industrial, sucessora dos senhores de escravo e dos exportadores de café, com total descompromisso com a justiça e a liberdade (BARROSO, 2009, p. 66).

Assim, a constituição estrutural dessa cultura jurídica beneficiou, de um lado, a prática do favor, do clientelismo, do nepotismo e da cooptação; de outro, introduziu um padrão de legalidade e de estrutura institucional inegavelmente formalista, retórico, eclético e ornamental. Incluindo suas características individualistas, antipopulares e não-democráticas, o liberalismo brasileiro haveria de ser contemplado igualmente por seu incisivo traço juridicista. Ademais, o cruzamento entre individualismo político e formalismo legalista delineou politicamente a montagem do cenário principal de nosso direito: o bacheralismo liberal, incapaz de situar-se criticamente diante do sistema jurídico.

A conclusão que se pode extrair dessa breve perspectiva histórica e da releitura questionada das ideias, das experiências normativas e das instituições jurídicas é a imediata necessidade de articular, na teoria e na prática, um projeto crítico de reconstrução democrática no direito nacional, o que envolve a problematização e a ordenação pedagógica de estratégias efetivas fundadas na democracia, no pluralismo e na interdisciplinaridade, que conduzam a uma historicidade social do jurídico, capaz de formar novos operadores e juristas orgânicos, comprometidos com a superação dos velhos paradigmas e com as transformações das instituições (públicas e privadas) arcaicas, elitistas e não-democráticas. Uma cultura jurídica que reflita, crítica e autocriticamente, ideias, padrões normativos e instituições, sintonizada com anseios e aspirações dos novos sujeitos sociais e comprometida com horizontes mais participativos e emancipadores, tudo em conformidade com a Constituição de 1988, o mais bem-sucedido empreendimento institucional da história brasileira, cujo corpo normativo orienta-nos na busca de uma democracia substantiva.

Entretanto, sabido que a esperança é um desejo imemorial que acompanha os homens desde sempre, é preciso que não nos deixemos iludir. Adverte-nos BOBBIO (1992, p. 24) que o "Estado Democrático e Estado Burocrático estão historicamente muito mais ligados um ao outro do que sua contraposição pode fazer pensar". O Povo é soberano e democrata quando da ocorrência das eleições; passado o período eleitoral volta a ser aquele refém de uma camada pequena da sociedade que passa a comandá-la, desconsiderando a sua satisfação na ação gestacional que foi confiada ao Estado. $\mathrm{O}$ instrumento dessa disfunção estatal é a burocracia.

A burocracia, preconizada por Max Weber, traduz-se, como visto, em método gerencial impessoal, que gera igualdade aos cidadãos, estável, seguro e racional. Com esses atributos, reafirma o Estado de direito, possibilita de forma eficaz o exercício da democracia formal e traz estabilidade ao sistema social por meio da efetividade do princípio da segurança jurídica. Sociologicamente, também unido ao Estado de direito, constitui-se a burocracia em estrutura de dominação racional-le- 
gal, que impede o exercício do poder pelo cidadão e afasta a concretização da democracia substancial. Assumindo, ainda, sua forma disfuncional, com ênfase nos meios empregados (onde o valor instrumental converte-se em valor final), qualifica-se pelo excesso de ritualismos, papelório, procedimentos e superconformidade às regras, impessoalidade, caso em que se torna verdadeiro obstáculo à ultimação de eventual estratégia assumida pelo ente estatal, que, não se pode perder vista, deve ser sempre voltada à realização do bem comum e nunca para os seus próprios interesses.

Restaurada a democracia, a Constituição ora vigente, promulgada em 05 de outubro de 1988, foi pródiga em estabelecer medidas para o fortalecimento do Poder Judiciário, objetivando, também, a melhoria da prestação jurisdicional.

A Emenda Constitucional $n^{\circ} 45 / 2004$, que instituiu a chamada Reforma do Poder Judiciário, ao contrário do alardeado, não trouxe em si solução para o crônico problema da ineficiência da máquina judiciária, inegavelmente abalada pela demanda de ações que é dirigida ao Poder Judiciário, notadamente em razão de seu papel de servir de canal de expressão para grupos que demandem a promoção dos objetivos comuns expressos pelos direitos fundamentais. Aliado a esse fato, PONCIANO (2008) aponta como determinantes no número de processos: (a) a disparidade gravíssima entre o discurso jurídico e a planificação econômica; (b) a instabilidade normativa e a inflação jurídica decorrente da produção legislativa desordenada e desenfreada pelo Executivo e Legislativo, inclusive contrariando a Constituição Federal; (c) a produção legislativa impulsionada unicamente pelo clientelismo político; (d) a omissão do Estado na implantação das políticas públicas necessárias à efetivação dos direitos garantidos pela atual Constituição; (e) a desobediência à Constituição e às leis pelo próprio poder público e (f) o aumento da burocracia estatal.

Assim, por força das profundas transformações econômicas e sociais que se deram ao longo do último século, aliadas àqueles outros fatores, as estruturas, competências e normas estatais experimentaram um crescente distanciamento da realidade social, até o ponto de a sociedade e os operadores do sistema jurídico declararem, à unanimidade, a existência de uma situação de crise do Judiciário.

Impende assentar que, de forma clara e precisa, deixou o legislador constitucional consignado na Lei Maior como princípios: razoável duração do processo, celeridade (art. $5^{\circ}$, inciso LXXVIII) e eficiência (art. 37), outorgando aos magistrados a tarefa de dizer o direito segundo as regras constitucionais de aplicação imediata, sem aguardar a palavra do Legislativo, como era até então. Extrai-se desse conjunto de normas encontrar-se implícito o princípio da boa administração - consagrado também, de forma expressa, nos artigos VIII e X da Declaração Universal dos Direitos do Homem e no artigo 41 da Carta de Direitos Fundamentais da União Europeia (Carta de Nice) -, o qual é idôneo a deflagrar para o jurisdicionado o direito subjetivo, de natureza fundamental, de exigir tal prática dos administradores da res publica.

Dessa contemporânea principiologia, infere-se, outrossim, que, no Estado 
democrático contemporâneo, a eficácia concreta dos direitos constitucional e legalmente assegurados depende da garantia da tutela jurisdicional efetiva, porque sem ela o titular do direito não dispõe da proteção necessária do Estado ao seu pleno gozo. A tutela efetiva é, portanto, não apenas uma garantia, mas, ela própria, um direito fundamental, cuja eficácia irrestrita é preciso assegurar, em respeito à própria dignidade humana (GRECO, 2012, p. 01). Como consectário lógico, tem-se que a garantia do acesso à Justiça não se esgota no direito de provocar o exercício da função jurisdicional, mas no fato de que a tutela pretendida seja oportunizada de forma eficaz e eficiente.

A esse propósito, importa distinguir o conceito de eficiência e eficácia, uma vez que a eficácia, na ciência do direito, denota a aptidão de uma lei ou ato jurídico de produzir efeitos. Aqueles termos estão sendo empregados neste estudo na esteira da ciência da administração e da economia, considerados básicos para o estudo da gestão das organizações. Com efeito, a norma técnica não-compulsória NBR ISO 9000:2005 ${ }^{474}$, de aplicação universal e da qual é subscritor o Brasil, fornece a seguinte definição para aqueles vocábulos:

- Eficácia: Extensão na qual as atividades planejadas são realizadas e os resultados planejados alcançados.

- Eficiência: Relação entre o resultado alcançado e os recursos usados.

Em geral, a eficiência está intimamente relacionada aos custos de realização do processo (tempo, gastos, instalações etc.).

Várias são as alternativas de combinação de eficácia e de eficiência den-

$\overline{474}$ A International Standard Organization - ISO (Organização Internacional de Padrões) é uma organização com sede em Genebra - Suíça e com escritórios em praticamente todos os países do mundo, que se ocupa em desenvolver normas voluntárias (não-compulsórias), tendo como objeto a maioria dos ramos tecnológicos (engenharia em geral, segurança, meio ambiente, responsabilidade social, qualidade etc.). A sua função é a de promover a normatização de produtos e serviços para que a qualidade destes seja permanentemente melhorada. O Brasil, como signatário, pode adotar as normas emitidas pela ISO, que são traduzidas para o português pela Associação Brasileira de Normas Técnicas (ABNT) e recebem um prefixo "NBR", caracterizando-as como normas brasileiras. O ano que se inclui é o da última revisão da norma. Dentre as normas ISO, destaca-se o conjunto (ou família) 9000, voltado especificamente para o tema gestão, o qual possui a seguinte lógica: ISO 9000:2005: fornece informações sobre a rationale da qualidade e define a terminologia a ser utilizada na Gestão da Qualidade; ISO 9001:2008: apresenta os requisitos universais para a gestão com qualidade; ISO 9004:2010: fornece orientação sobre aprimoramento contínuo da qualidade, apresentando complementações aos requisitos da NBR ISO 9001:2008 (básicos ou mínimos), sofisticação ou alargamento da sua abrangência. Convém ressaltar que existem outros modelos de sistemas de gestão; todavia, praticamente todos convergem para os mesmos elementos de gestão sustentável. 
tro de um processo de trabalho de uma organização. Por exemplo: uma sentença proferida com observância de todas as garantias substanciais, mas que no seu iter procedimental não foi observado o prazo razoável, resulta em processo eficaz, porém ineficiente. Ou um particular atendimento, cuja informação não é fornecida tendo em vista que o processo judicial não foi localizado no cartório judiciário e, além disso, o atendimento completo é realizado em duas horas. Nesse caso estamos diante de um processo ineficaz e ineficiente.

Maria Elisa Macieira e Mauriti Maranhão (MACIEIRA; MARANHÃO, 2010, p. 34) apresentam outra forma de abordar eficiência e eficácia, trazendo luz à sua melhor compreensão:

\begin{tabular}{|l|l|}
\hline Qualificação & Ação descritora da condição \\
\hline Eficaz & $\begin{array}{l}\text { Executa corretamente aquilo } \\
\text { que é feito (não necessariamente } \\
\text { o que é feito é a real necessidade } \\
\text { do destinatário final do produto } \\
\text { ou serviço). }\end{array}$ \\
\hline Eficiente & $\begin{array}{l}\text { Alcança os objetivos planejados } \\
\text { (considerando as necessidades } \\
\text { dos usuários) desenvolvendo } \\
\text { no destinatário final a percep- } \\
\text { ção de satisfação com o serviço } \\
\text { prestado. }\end{array}$ \\
\hline Eficaz e eficiente & $\begin{array}{l}\text { Faz, sob custo compatível, o que } \\
\text { realmente precisa ser feito. }\end{array}$ \\
\hline
\end{tabular}

Para aqueles autores, que detêm ampla experiência e conhecimento em implementação de sistemas de gestão em unidades do Judiciário fluminense, a experiência mostra que:

Em geral, algumas organizações fazem mais do que precisa ser feito, deixam de fazer algumas coisas essenciais e as coisas que fazem não são nem eficientes nem eficazes. É uma combinação explosiva de insatisfação dos usuários (que se frustram por não terem as suas necessidades atendidas) com desperdício (realização de atividades desnecessárias, que não agregam valor).

Em resumo, combinar eficiência e eficácia dos processos de trabalho significa atender às necessidades dos usuários dos próximos processos, sob custo mínimo, e obter a rentabilidade capaz de manter a instituição permanentemente reconhecida. Em termos práticos, a adequada combinação de eficácia e eficiência determina completamente a qualidade do processo. 
Importa consignar, outrossim, que consoante o padrão técnico NBR ISO 9000:2005, sistema (ou modelo) é o conjunto de elementos que estão inter-relacionados ou interativos e sistema de gestão são atividades coordenadas para dirigir e controlar uma organização ou, em outras palavras, para estabelecer política e objetivos, e para atingir estes objetivos. O termo qualidade, adicionado ao sistema de gestão, tal como preceitua aquela norma técnica, é o conjunto de características diferenciadoras de um produto ou serviço que satisfazem os requisitos estabelecidos pelo sistema de gestão para a satisfação do cliente.

Quanto maior a quantidade de recursos (pessoas, dinheiro, bens tangíveis e intangíveis), mais complexo se torna o processo de gestão. A complexidade aumenta quando se está diante de sistemas sociais considerados como não-lineares, ${ }^{475}$ tal como é o Judiciário. Essa é uma das razões que faz com que a gestão constitua uma atividade especializada nas organizações, a exigir, portanto, uma expertise, particularmente da alta cúpula administrativa, que é quem efetivamente delibera, ou em outras palavras, define os objetivos a serem alcançados e o meio hábil a cumpri-los. São os indivíduos que tomam decisões, que afetam o destino das organizações por eles dirigidas. Aliás, conforme salienta o guru da qualidade japonesa Kaoru

475 Embora algumas instituições sejam milenárias (igrejas e forças armadas, por exemplo), foi a partir do final do século XIX que alguns estudiosos manifestaram curiosidade para compreender como os sistemas organizacionais são estruturados e como fazê-los funcionar adequadamente. Anteriormente, considerava-se como sistemas apenas aqueles de natureza inorgânica, aos quais se aplicavam as leis das ciências exatas conhecidas à época (matemática, física, química etc.). Os sistemas inorgânicos, pelo fato de serem regulados por leis da ciência exata, apresentam comportamento linear, com relações de causa e efeito bem definidas (por exemplo, para aumentar a concentração de sal em determinada solução para X\%, basta adicionar Y gramas de sal). Evidente que o comportamento linear torna o tratamento dos sistemas inorgânicos mais simples e plenamente previsível. Com o surgimento dos sistemas sociais (povoados por homens), as relações de causa e efeito passaram a ser de outra ordem, não mais lineares, tornando-se muito mais complexas e, por isso mesmo, maior se justifica a presença de conhecimentos multidisciplinares para lidar com as variáveis em jogo. O Poder Judiciário e a sociedade são sistemas sociais que se realimentam - ou que deveriam realimentar-se - a partir das grandezas em jogo. No caso do Judiciário, poder-se-ia, como exemplo possível (e muito desejável), desenvolver modelos para estimar o crescimento da demanda judiciária, a partir do aumento de determinada população (vegetativo ou decorrente de um fato extraordinário, como a instalação de um polo industrial). Evidente que se o Judiciário utilizasse tais modelos muitos dos problemas de congestionamento que aquele vem suportando (infelizmente comuns) poderiam ser atenuados. Mas não se pode perder de vista que, por se tratar de sistemas sociais, as projeções seriam apenas aproximadas. Em outras palavras, não é possível prever com exatidão o comportamento dos sistemas sociais, em face das múltiplas e permanentes interações das relações de causa e efeito. Desse modo, pode uma determinada política pública implementada causar modificações iniciais que, por sua vez, modificam o sistema e, por consequência, tornam inválidas todas as previsões anteriormente feitas. Por isso, a importância de avaliar o resultado, identificando diferenças entre o efeito concreto da ação (o ser) e o planejado. 
Ishikawa, citado por CARAVANTES (1997, p. 32): “A qualidade é uma revolução da própria filosofia administrativa, exigindo uma mentalidade de todos os integrantes da organização, principalmente da alta cúpula".

Há senso comum quanto à generalidade de funcionamento das organizações serem associadas a sistemas sociais. A figura que se segue mostra um esquema da concepção biológica dos sistemas, dotando-o de um mecanismo de retroalimentação característico de todo ser vivo.

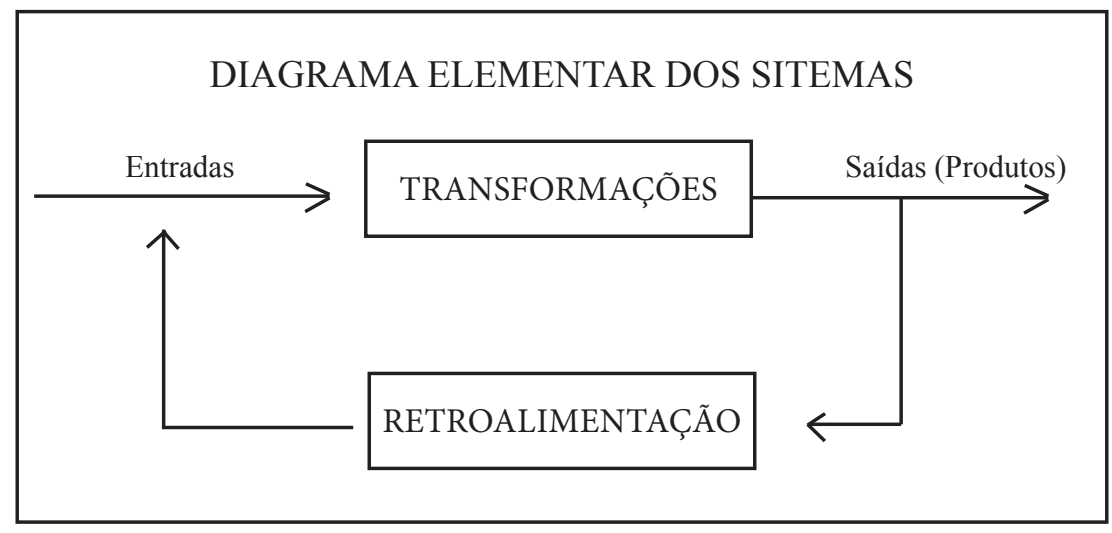

Esse processo, que deve ser estabelecido entre as organizações e a sociedade, será responsável pela estratégia a ser definida - e redefinida, se for o caso - por aquelas. Essa ideia que está alinhada com os ditos sistemas abertos contrapõe-se aos primados do modelo burocrático, adotado pelo Judiciário brasileiro, que encerra uma autorreferência e se concentra tão-somente no processo enquanto fim, desconsiderando a eficiência envolvida.

A moderna concepção de gestão da Qualidade Total ${ }^{476}$ desenvolveu-se nos anos 50 a partir dos trabalhos de Armand V. Feigenbaum, Joseph M. Juran e Winston Edwards Deming. Assim, complementarmente ao conceito adotado pela ISO, que tem como função a normatização de produtos e serviços para que a qualidade destes seja permanentemente melhorada, passamos a trazer o entendimento acerca do que vem a ser qualidade, consoante a melhor doutrina.

Para Feigenbaum apud BUENO (2010, p. 15), a qualidade implica a perfeita satisfação do usuário, podendo aquela ser conceituada como "uma maneira de se gerenciar os negócios da empresa, sendo que o aprimoramento da qualidade só pode ser alcançado em uma empresa com a participação de todos".

JURAN (1991, p. 45), consultor conceituado internacionalmente em gestão da qualidade, define que qualidade é a "adequação do produto ou serviço ao uso",

\footnotetext{
${ }^{476} \mathrm{O}$ controle de qualidade é dito total por englobar todas as pessoas e ser exercido em todos os lugares da organização, envolvendo todos os níveis e todas as unidades.
} 
ou seja, à necessidade do cliente.

Por seu turno, Deming apud GAZ (2004, p. 5), conhecido como o guru da qualidade desde 1950, diz que: "Em vez de estabelecer cotas numéricas, a administração para a qualidade deveria trabalhar para melhorar o processo. O fluxograma indica um processo. O problema é saber de que maneira melhorá-lo".

Para Falconi apud CAMPOS (1992, p. 02), "um produto ou serviço de qualidade é aquele que atende perfeitamente, de forma confiável, de forma acessível, de forma segura e no tempo certo às necessidades do cliente".

Observa-se que, apesar do princípio da eficiência insculpido expressamente na Carta Magna e do movimento no Brasil a favor da qualidade como parâmetro a ser perseguido nas organizações, o Poder Judiciário, mesmo diante de sua alta complexidade organizacional, retarda em racionalizar a sua administração. Exemplo disso é que só a partir da Resolução do Conselho Nacional de Justiça (CNJ) de ${ }^{\circ} 70$, de 18/03/2009, o Judiciário divulgou seu planejamento estratégico, uma imprescindível ferramenta de gestão. Insta consignar que o processo de gestão estratégica constitui um esforço disciplinado para produzir decisões e ações fundamentais sobre o que uma organização é, aonde quer chegar, e utilizando quais meios. Portanto, pode-se dizer que uma organização sem estratégia é uma organização sem rumo, bem como que, ao pretendermos agilizar um processo sem ao menos um rumo estabelecido, o que se obtém é uma aceleração da confusão muito possivelmente já existente. Sob outro prisma, de nada adianta um planejamento estratégico sem os efetivos meios de controle acerca da qualidade do serviço prestado, estando ínsito neste conceito, conforme demonstrado, a satisfação do destinatário final do serviço.

O princípio da boa administração, previsto expressamente, como apontado alhures, em importantes documentos internacionais e implícito em nosso sistema constitucional, há de expandir suas fronteiras para compreender não só uma lógica economicista, que restringe sua avaliação aos outputs da função. O Estado democrático de direito deve ser instrumento eficaz e eficiente, a serviço do todo social, indiscriminadamente. Para isso, os fundamentos e as modernas técnicas administrativas apenas se justificam se toda a estrutura funcional tiver conhecimento e planejar seu trabalho em conformidade com as demandas da sociedade, sob a primazia dos valores humanos e sociais, submetendo o econômico à dinâmica e necessidades sociais (PASOLD, 2007, p. 35). Como consectário dessa assertiva, tem-se que a participação social há de ser promovida por ocasião das escolhas públicas, da implementação das políticas de gestão correspondentes, ainda no momento da avaliação.

É essa ampliação de sentido da ideia de qualidade que tem evidenciado a insuficiência do modelo burocrático e do argumento que firma a legitimidade da ação estatal na operational autothority, já que desconsidera o ponto assinalado por BOURGON (2009), segundo o qual o próprio conceito do resultado desejável em tempos de Estado democrático de direito abarca a exigência da presença da sociedade como agente de deliberação. Afinal, democracia, na lição de Bobbio, é o "poder 
em público" (BOBBIO, 2000, p. 386).

Assim, a eficiência como princípio posto à administração judiciária há de incorporar o incremento da cidadania ativa como valor no processo de decisão, tanto quanto aqueles outros outputs da atuação estatal, quantitativamente aferíveis.

José Afonso da Silva parece caminhar na direção das teorias da administração quando afirma que o conceito de eficiência não é jurídico, mas econômico, servindo para qualificar atividades que correspondam, numa concepção muito geral, a fazer acontecer com racionalidade, o que implica medir os custos que a satisfação das necessidades públicas importam em relação ao grau de utilidade alcançado, servindo, também, para orientar a atividade administrativa, no sentido de conseguir os melhores resultados, com os meios escassos de que dispõe e a menor custo (SILVA, 2012, p. 671).

Se boa administração envolve a abertura do direito a um modelo de administração funcional e à democratização da função administrativa, isso exigirá do Judiciário a cunhagem de uma postura compatível com o novo desenho de ação inclusivo, num contexto oposto àquele firmado na verticalidade das relações, tão caro ao modelo burocrático. Nessa quadra, o emprego do conceito essencialmente democrático de governança, mencionado pela primeira vez pelo Banco Mundial, em 1992, como atributo desejável à administração pública, restou disseminado, podendo ser descrito como uma estratégia de governo que, reconhecendo suas limitações, admite o envolvimento e a necessária contribuição de outros atores sociais, cidadãos ou organizações, que integrem a constelação de agentes qualificados ao enriquecimento do processo de decisão ou, de outro modo, pode ser descrito como o modo pelo qual os valores subjacentes de uma Nação são institucionalizados.

Apesar dessas proposições, o Judiciário, mesmo recebendo com a nova ordem política novos poderes, maior independência, desatrelando-se do Poder Executivo, marchou rumo ao enfrentamento dos novos direitos sem propostas novas, sem abrir mão de suas prerrogativas, mantendo-se no seu silencioso feudalismo. MANCUSO (2010), a esse respeito, alerta para a prática de uma política judiciária equivocada calcada no incessante aumento da estrutura física, focada na vertente quantitativa do problema, isto é, no volume excessivo de processos: ao aumento da demanda (mais processos), se intenta responder com um incessante crescimento de base física do Judiciário (mais fóruns, mais juízes, mais equipamentos de informática, enfim, mais custeio), sem que se dê conta de que tal "estratégia", desacompanhada de uma gestão eficiente, muito se aproxima do popular "enxugar gelo", a par de agravar a situação existente, na medida em que o aumento da oferta acaba por alimentar a demanda, disseminando junto à população a falácia de que toda e qualquer controvérsia pode e deve ser judicializada, quando, antes, caberia expandir a informação quanto ao acesso a outros meios, auto e heterocompositivos, além de outras medidas calcadas em um plano nacional de política judiciária, que considere todas as concausas que afetam o complexo sistema Judiciário e as várias interfaces 
desse mesmo sistema.

Seis anos depois da Constituição de 1988, veio a Reforma do Poder Judiciário, via Emenda Constitucional no 45/2004, e com ela a criação do Conselho Nacional de Justiça, chamado de controle externo do Judiciário. Objetivou o CNJ responsabilizar-se pela sujeição do Poder Judiciário à disciplina administrativa por ele imposta, mantidas as decisões judiciais fora do seu alcance, e democratizar o Poder, submetido a uma verticalização administrativa incompatível com qualquer modelo de administração moderna. Consequência direta desse quadro é a de que a gestão era realizada de forma descontinuada, a depender do administrador de plantão, e as "estratégias" contemplavam, na maioria das vezes, projetos pessoais daquele, sem considerar qualquer racionalidade sistêmica nas ações empreendidas. De forma geral, eram prestigiadas ações imediatistas, em detrimento de ações de médio ou longo prazo.

Diante desse quadro, uma das medidas prioritárias adotadas pelo $\mathrm{CNJ}$ foi a de impor planejamento estratégico, através da já referida Resolução $n^{\circ} 70 / 2009$, por meio da qual se destacou a necessidade do estabelecimento, por todos os tribunais, de metas de curto, médio e longo prazos, que deveriam estar associadas a indicadores de resultado e a planos de ação previamente estabelecidos, levando o Poder Judiciário a superar a prática de funcionar sem projetos, sem saber o que está fazendo, sem qualquer controle efetivo sobre o resultado (ainda que meramente quantitativo) de sua administração e de suas realizações. Sobre esse contexto caótico encontrado no Poder Judiciário, a então Corregedora do Conselho Nacional de Justiça, ministra Eliana Calmon, manifestou-se (CALMON, 2012, p. 5):

Dentro dos Tribunais de Justiça, vinte sete ilhas isoladas, foram encontradas práticas administrativas absolutamente condenáveis sob o aspecto técnico, descontinuadas e sem responsabilização dos administradores. Tudo era feito de forma pessoal e na base do improviso. Era imprescindível agregar, uniformizar e planejar para assim caminhar junto, vencendo diferenças abismais entre os Tribunais e, o que é pior, dentro do mesmo Tribunal varas ou gabinetes inviabilizados por acúmulo de processos, falta de equipamentos e falta de gestor, situações por vezes críticas com direto reflexo na produção da atividade-fim.

A falta de uniformidade, assim como de transparência na prática judiciária, levou o CNJ a adotar, como objetivo macro, vencer o silencioso proceder do Judiciário, a chamada caixa preta, introduzindo a publicidade como norma das práticas administrativas. Criou, assim, cadastros importantes para traçar o perfil e dimensionar o tamanho da Justiça brasileira, tais como o Justiça em Números e o Justiça Aberta, este último a cargo da Corregedoria Nacional, e estabeleceu metas a serem seguidas pelos tribunais. Tentou, outrossim, democratizar a burocracia daquele Poder criando 
os recursos para que se abrisse ao controle social, descuidando-se, todavia, de prever mecanismos de participação em deliberações e de ausculta dos resultados efetivamente obtidos pelos destinatários das ações empreendidas (feedback), os quais deveriam servir como vetores para a redefinição da estratégia e das metas da organização. Em outras palavras: buscou-se um resultado quantitativo, mas não há qualquer previsão de um procedimento dentro do sistema para verificar se a instituição está, de fato, gerando o resultado qualitativo que deve ser esperado. Imperioso anotar que não é possível fazer juízos de valor consistentes quando se reduz o campo de observação de processos cujos níveis de complexidade são muito elevados: há que se levar em consideração que a expectativa externa que se apresenta ao Judiciário é a de que ele funcione como instância moral, que não se expressa apenas nas demandas de cláusulas jurídicas, mas também na confiança reinante da população na justiça (MAUS, 2010, p. 23). A introdução de aspectos morais e de valores a serem observados pelo Judiciário dota este não só de um protagonismo no jogo democrático, mas também de uma igual responsabilidade de criar mecanismos para que seja passível de críticas, de modo que seja factível verificar se, efetivamente, está alinhado com as aspirações constitucionais. Afinal, o Judiciário, como ente estatal, não se legitima pela sua só existência, mas pelos resultados profícuos que traz para a sociedade. Nas palavras de GORDILHO (2001, pp. 84-85), "um sistema administrativo pode se afigurar a um jurista uma magnífica arquitetura de construção da ordem, mas se a comunidade a que ele serve não tem a mesma percepção, o sistema não tem valor, donde uma das primeiras causas possíveis de um parassistema”.

Amartya Sen (SEN, 2011, p. 117), na obra A idéia de Justiça, referindo-se às instituições e ao processo substancial democrático, assevera que a sociedade não pode simplesmente entregar a tarefa da justiça a algumas das instituições e regras sociais que entende como precisamente corretas e depois aí descansar, libertando-se de posteriores avaliações pessoais ou de moralidade. Precisamente quanto ao papel das instituições nesse jogo democrático, preconiza, ainda, que "a democracia tem de ser julgada não apenas pelas instituições que existem formalmente, mas também por diferentes vozes, de diversas partes da população, na medida em que de fato possam ser ouvidas".

Não é ocioso consignar, outrossim, que o ritmo incessante que conduz o objetivo de se cumprirem metas, pontuais e fragmentadas de um todo existente, leva a essa entropia que se observa no Poder Judiciário. Movido pelo presente e saturado pelo instantâneo, vive o Judiciário como se o passado não tivesse nada a dizer e o futuro fosse demasiado incerto para ser construído. Assim, dedica todos os esforços e atenção à tramitação daqueles processos estabelecidos em metas fragmentadas, desviando a atenção para todo o acervo existente, que, um dia, se o administrador de plantão não mudar de direção, integrará as novas metas que vierem a ser editadas. Com isso, legitima-se a ausência de uma política administrativa sustentável e continuada junto àquele Poder, posto que, cumprindo os atos administrativos expedidos 
pelo CNJ, sente-se o Judiciário confortável e também desestimulado a procurar encampar uma política judiciária racional e eficiente, que o leve a sair desse círculo vicioso rumo a um conjunto de práticas de boa administração que o conduza a um desejado círculo virtuoso.

O artigo 37 da CF, com a redação da $E C n^{\circ}$ 19/1998, vinculou a promoção de magistrados pelo critério de merecimento à aferição de seu desempenho, segundo critérios objetivos de produtividade e presteza no exercício da jurisdição e pela freqüência e aproveitamento em cursos oficiais ou reconhecidos de aperfeiçoamento. A capacitação é, portanto, a tônica da política administrativa implementada a partir da Constituição, sendo exigida deste o vitaliciamento. Nesse passo, a Escola de Magistrados, vinculada ao STF, editou a Resolução $n^{\circ}$ 02/2007, considerando o período de vitaliciamento como etapa do concurso de ingresso da magistratura.

Iluminado pelas novas diretrizes constitucionais, atentou o $\mathrm{CNJ}$ para a necessidade de sistematização de aspectos relacionados à capacitação do magistrado. No que se refere à seleção, formação e aperfeiçoamento dos juízes, foi editada a Resolução $n^{0} 64 / 2008$, que dispõe sobre o afastamento de magistrados para fins de aperfeiçoamento profissional, a que se refere o artigo 73, I, da Lei Complementar $\mathrm{n}^{\mathrm{o}}$ 35, de 14 de março de 1979 (Lei Orgânica da Magistratura Nacional). Também fez editar a Resolução $n^{0} 75 / 2009$, na qual regulamentou de forma minudente o concurso público a ser realizado por cada tribunal para seleção de magistrados, deixando a seu cargo, ainda, a preparação da fase de formação, na qual deverão ser ministradas matérias próprias das Ciências Sociais, sem denotar, contudo, qualquer preocupação com as ciências afetas à temática da administração judiciária. Intenta-se, assim, dar ao futuro magistrado formação tão-somente humanitária, de todo necessária, olvidando-se daquelas que agregariam valor no exercício de suas funções administrativas, enquanto gestor.

Desse conjunto de normas, do qual se depreende que foi preterida a importância da questão da expertise necessária para administrar as complexas variáveis relacionadas à função administrativa judiciária, destaca-se também a Resolução do $\mathrm{CNJ}$ de $n^{\circ} 49 / 2007$. Por meio deste ato normativo previsão para que os órgãos do Poder Judiciário relacionados no art. 92, incisos II ao VII da Constituição Federativa do Brasil, passassem a organizar em sua estrutura unidade administrativa competente para elaboração de estatística e plano de gestão estratégica do Tribunal. Assevera, ainda, que a referida unidade será composta preferencialmente (e não obrigatoriamente) por servidores com formação em direito, economia, administração, ciência da informação, sendo indispensável servidor com formação em estatística. Tal órgão terá a incumbência de enviar dados para o CNJ, quando solicitado, a fim de instruir ações (decerto de forma monopolítica, vale dizer, sem qualquer participação dos atores sociais) na política judiciária nacional. Pelo teor daquele documento, enfim, observa-se que o objetivo da unidade de estatística e de gestão estratégica é tãosomente munir os detentores do poder de deliberação dos resultados em número 
mensurados, a fim de que se possa proceder a uma avaliação institucional quanto ao número de processos julgados e aqueles ainda pendentes de julgamento para que, ao final, sejam promovidas ações que visem a otimizar o julgamento do acervo exponencial remanescente. Observa-se dessa sistemática que não há qualquer compromisso com o resultado quantitativo obtido. Para atingir a qualidade de que se está a falar, faz-se necessária, como assaz mencionado, a competência gerencial, não somente para planejar e implementar ações que visem à obtenção da qualidade do serviço, quanto para auscultar os resultados e as informações (feedback) durante e após a implementação, e retroalimentar o sistema para corrigir os eventuais desvios, que sempre ocorrem, particularmente quando o que se está em jogo é um sistema social.

Imperioso consignar que, caso não haja uma mudança de cultura que passe, necessariamente, pela formação dos profissionais de direito, nenhuma reforma que se pretenda será bem sucedida. Nessa esteira, seria de bom alvitre que as Escolas da Magistratura dedicassem parte de seu conteúdo programático a essa questão.

Rogério Bento (NASCIMENTO, 2008, p. 194), ao discorrer sobre os obstáculos enfrentados para a concretização de uma aspirada reforma do sistema de gestão do Judiciário, apontou como uma das causas a prevalência do que ele denominou de uma "contaminação de lógica instrumental". In verbis:

[...] Um segundo problema é o que eu chamo de contaminação de lógica instrumental. Trata-se de pensar a prestação única e exclusivamente a partir da perspectiva de seus agentes. Ou seja, olhando para dentro da prestação jurisdicional, sem olhar para seu resultado em relação à sociedade. Significa fazer uma reflexão limitada ao atendimento das próprias estruturas corporativas envolvidas na prestação jurisdicional, preocupada apenas com o que é bom para o melhor funcionamento do ponto de vista do agente público, sem levar em conta o que seja um bom funcionamento pela perspectiva da sociedade, do participante dos processos levados ao Judiciário. Essa visão, muito comum, costuma reduzir o debate sobre reforma da gestão do sistema judiciário a uma discussão sobre como reduzir a demanda por julgamento ou como agilizar o atendimento à demanda existente, sem tocar no problema da qualidade da prestação jurisdicional.

Apesar dessas considerações, deve-se aplaudir o fato de que o Judiciário tem ensaiado sair do seu hermetismo ao estabelecer, por exemplo, convênios com o objetivo de melhorar os seus serviços. Nesse sentido o convênio firmado, em 2009, com o Banco Central do Brasil, que contou com o apoio da Federação Brasileira dos Bancos, com o objetivo de aprimorar o sistema BACEN-JUD, revolucionando o sistema de penhoras até então utilizado. Esse é um exemplo de que as parcerias formadas pelos diversos atores sociais são muito bem-vindas, quando o que se está em foco é otimizar os procedimentos e reduzir os custos empregados na sua realização 
para se obter um resultado organizacional de excelência.

Outras ações foram adotadas pelo CNJ - das quais destaca-se o Movimento pela Conciliação -, o qual também editou inúmeras resoluções para resolver ou minorar problemas que muito afligem a população e que envolvem o cumprimento dos princípios elencados no art. 37 da Constituição da República. Todas essas iniciativas são louváveis, mas ainda são pontuais e esparsas, e não surtiram o efeito esperado de prestar, de forma sustentável, duradoura e integrada ao sistema de justiça uma prestação jurisdicional de qualidade, decorrente da melhoria contínua do sistema. As ações de mutirões, por exemplo, apesar de importantes, não cumprem esse papel: são metas de manutenção do próprio sistema vigente. É preciso que tal medida não seja importante de per si, mas porque assim foi considerada dentro de um sólido e racional planejamento estratégico, que leve em conta todas as interfaces do sistema. Sendo importantes para o sistema judicial, aquelas ações não devem ser ocasionais, mas continuadas, até quando consideradas benéficas ao sistema judiciário e à sociedade. O mesmo se diga à questão do fomento dos demais meios complementares de acesso à Justiça.

Quanto ao resultado das medidas (fragmentadas) adotadas pelo CNJ, a Ministra Eliana Calmon (CALMON, 2012, p. 7), no final do seu mandato frente à Corregedoria do CNJ, afirma, com um certo desalento, que:

As metas ainda estão sendo cumpridas, aqui e ali, com as dificuldades de sempre, falta de recursos financeiros, falta de pessoal, servidores despreparados e, na minha visão, em muitas situações falta de crença na possibilidade de mudar com atitude e determinação, ingredientes primeiros para qualquer alteração que se queira implementar.

A cada ano o CNJ faz uma avaliação do cumprimento das metas e, a partir daí, divulga os resultados da atuação de cada Tribunal, com total transparência, estimulando o empenho dos Tribunais. Entendemos lento, bem lento, o enfrentamento e cumprimento das metas, mas o certo é que o trabalho já começou e prossegue.

Com a Constituição de 1988, cujo texto é abundante em normas programáticas, marcado pela redemocratização e pelo constitucionalismo que inseriu o Judiciário no centro da arena pública, a demanda pelo serviço público de justiça, já se anotou, aumentou vertiginosamente. De fato, consoante o Relatório Justiça em Números 2011, publicado em outubro de 2012 (CNJ, 2012, pp. 447-448), a tramitação total da movimentação processual em todos os ramos do Judiciário nacional (exceto no STF e Conselhos), alcançou, naquele ano, cerca de 90 milhões de processos. Desse quantitativo 71\% já estavam pendentes desde o início do ano e os processos restantes ingressaram durante o ano, valendo isso a dizer que o montante apurado equivale à soma dos casos novos e dos casos pendentes que aguardam o 
julgamento pelo Judiciário de nosso país. Esse acervo exponencial, frente a uma instituição que pouco se modernizou - apesar da ampliação de despesas orçamentárias e de servidores - causou um déficit gradativo de processos entrados e processos julgados, resultando no conhecido congestionamento da justiça, ante a formação de um acúmulo de processos à espera da prestação jurisdicional; esse acúmulo foi denominado pelo CNJ de taxa de congestionamento e tem como finalidade mensurar se a Justiça consegue decidir com presteza as demandas da sociedade, ou seja, se as novas demandas e os casos pendentes de períodos anteriores são finalizados ao longo do ano. O referido relatório aponta que o índice global da taxa de congestionamento do Judiciário brasileiro é de 73,6\%, percentual que aumentou em cerca de 3,6\% em relação a 2010.

Diante dessa perspectiva que aponta para um demandismo avassalador, impende ressaltar que a morosidade judicial se mostra como o principal fator de desencanto social, posto que a justiça tarda e, considerando esse só fato, pode sim falhar. A prestação jurisdicional a destempo corrói a própria autoridade do Poder Judiciário, afastando dos tribunais grande parte da população.

Questão que afeta profundamente o desenvolvimento econômico e social de um país é a capacidade do Judiciário de se apresentar como uma instância legítima na solução de conflitos que surgem no ambiente social, empresarial e econômico. Partindo dessa premissa, foi criado pela FGV o Índice de Confiança na Justiça no Brasil - ICJBrasil, que é um levantamento estatístico trimestral de natureza qualitati$v a$. Tal índice objetiva retratar o grau de "confiança" da população no Poder Judiciário, vale dizer, se o cidadão acredita que aquela instituição cumpre a sua função com qualidade, se faz isso de forma em que os benefícios de sua atuação sejam maiores que os seus custos e se essa instituição é levada em conta no dia a dia do cidadão comum. A comunidade alvo daquela pesquisa é constituída de habitantes, com 18 anos ou mais, de oito unidades federativas (UF): Amazonas, Pernambuco, Bahia, Minas Gerais, Rio de Janeiro, São Paulo, Rio Grande do Sul e Distrito Federal, que juntas representam aproximadamente $55 \%$ da população do país, segundo dados do Censo 2010 do IBGE. Pois bem, o relatório ICJ-Brasil do $4^{\circ}$ trimestre de 2012, disponibilizado no sítio eletrônico da FGV no $1^{\circ}$ trimestre de 2013, (FGV, 2013, p. 12-16) demonstra que:

1) $50 \%$ dos entrevistados já utilizou os serviços do Judiciário.

Esclarece aquele estudo que as ações apontadas pelos entrevistados relacionam-se aos anos anteriores a $2000(10 \%)$, aos anos de 2000 a $2006(21 \%)$ e 2007 a 2010 (69\%); que, relativamente à satisfação com o Poder Judiciário, segue a tendência que vem sendo observada nos períodos anteriores no que diz respeito à má avaliação do Judiciário como prestador de serviços públicos: para 90\% dos entrevistados o Judiciário é moroso, resolvendo os conflitos de forma lenta ou muito 
lentamente. Além disso, 79\% disseram que os custos para acessar o Judiciário são altos ou muito altos e $69 \%$ dos entrevistados acreditam que o Judiciário é difícil ou muito difícil para utilizar. Outros dois problemas apontados pelos entrevistados são a falta de honestidade (64\% dos entrevistados consideram o Judiciário nada ou pouco honesto) e a parcialidade (62\% dos entrevistados acreditam que o Judiciário é nada ou pouco independente). Não obstante a má percepção do Judiciário, a maioria dos entrevistados em questão declarou que procuraria o Judiciário para resolver os conflitos em que foram envolvidos.

2) $37 \%$ dos entrevistados declara confiar no Poder Judiciário.

Comparando a confiabilidade no Poder Judiciário com a confiabilidade nas outras instituições (Partidos Políticos, Congresso Nacional, Ministério Público, Polícia, Governo Federal, Imprensa escrita, Grandes empresas, Emissoras de TV, Igreja Católica, Forças Armadas), depreende-se do relatório em questão que o Poder Judiciário só é mais confiável que as Emissoras de TV, o Congresso Nacional e os Partidos Políticos, tendo ficado abaixo do patamar da Polícia.

Para aqueles que não acionariam o Judiciário, ainda que houvesse necessidade, o argumento mais frequente relaciona-se aos aspectos da administração da justiça, considerando que $65 \%$ não o fariam por julgarem que a resolução do problema demoraria muito, que seria caro ou porque não confiam no Judiciário para a solução dos conflitos.

Alinhados com os dados estatísticos que demonstram o baixo índice de confiabilidade da população na Justiça, Maria Teresa Sadek e Rogério Bastos Arantes (SADEK; ARANTES, 1994, p. 39), avaliando o quadro de crise do Judiciário, observam que esta debilidade torna-se ainda mais gritante quando se leva em consideração que apenas cerca de $33 \%$ das pessoas envolvidas em algum tipo de conflito dirigem-se àquele ente estatal em busca de uma solução para seus problemas. Tal dado é extremamente preocupante, uma vez que indica tanto um descrédito na justiça quanto o fato de que, se a maior parte daqueles que poderiam recorrer ao Judiciário o fizessem, o sistema estaria próximo ao colapso.

Apresentado o panorama da crise da Justiça brasileira, é preciso asseverar que: a) elaborar políticas públicas no intento de concretizar o princípio da boa administração, passa necessariamente pelas reformas legislativas, que têm ocorrido em larga escala, mas não só. A razoável duração processual, por exemplo, não é uma oferta, ou melhor, um resultado que se busca pelo fim, mas desde a gênese do processo. Partindo dessa proposição, a tempestividade será uma realidade que se concretizará em todo o iter processual; b) devam existir estatísticas qualitativas idôneas que avaliem o desempenho do Judiciário e, principalmente, que seus dados sejam efetivamente considerados como indicadores para se buscar a alta performance do seu sistema como um todo: da atividade meio à atividade fim. 
Em uma situação de crise, como a que se enfrenta no Judiciário e em outras áreas da Administração Pública, não se pode mais admitir a ação episódica, apoiada na metodologia do ensaio e erro, sendo imperioso que a gestão se opere através de ações estrategicamente planejadas com adequação aos meios e necessidades diagnosticadas na realidade. A expertise necessária para lidar com o tema gestão tem sido olhada com muito preconceito, o que pode ser concebido como verdadeiro obstáculo ao desenvolvimento racional da administração judiciária. Não há mais espaço para se insistir no modelo técnico-burocrático, ou, ao menos, para se insistir naquilo que o referido modelo apresenta de disfuncionalidade. Urge que se construa o Judiciário democrático, aberto à ampla participação da sociedade e com magistrados, principalmente da alta cúpula, adredemente preparados para que não só entendam os novos signos das modernas técnicas de gestão pública, mas também que compreendam a necessidade de sua aplicação na política da administração judiciária e, uma vez internalizada essa cultura, passem a ter uma visão sistêmica, integrada de seu funcionamento, saindo do isolamento científico, metodológico e racionalizado, sendo considerado este último predicado, contemporaneamente, como verdadeira patologia que conduz à simplificação do saber. De fato, a racionalização, segundo MORIN (2011, p. 70), encerra o real em um sistema de ideias coerentes, fato que induz a que seja ignorada a ação dialógica da racionalidade. Com efeito, tudo aquilo que, no mundo real, contradiz aquele sistema coerente é afastado. Prossegue o filósofo afirmando que, com freqüência, a racionalização se desenvolve na própria mente dos cientistas e que se deve lutar cem cessar contra a deificação da razão, sendo esta, entretanto, a única ferramenta confiável, à condição de ser não só crítica, mas autocrítica.

Construído esse novo cenário, decerto se suavizarão, ou quiçá, desaparecerão os contornos liberais absolutistas do Judiciário, dando lugar àqueles próprios de um Estado democrático de direito, que conclama não ser lícito ao jurista se abrigar atrás dos muros da técnica dogmática e formalista para isentar-se da responsabilidade, que é sua, em relação à sociedade. Toda a sua ação e visão devem ser orientadas para esta, para o bem comum e nunca para seu próprio interesse. Tem-se a semente de um raciocínio que - quiçá - até o final do século XXI se desenvolverá por completo: a de que a legitimidade do agir estatal repouse não só no fato de que sua ação se encontre coerente com o que preconiza a lei (ou na oferta de serviço público que reverencie tão-somente a quantidade), mas também na sintonia com seus compromissos finalísticos e nos resultados qualificativos alcançados a partir de suas estratégias racionais e eficientes de atuação. Esperemos, pois, que o pêndulo da história se movimente.

\section{Conclusão}

A existência de uma crise no Poder Judiciário é consenso. A questão, no entanto, é que, diante da necessidade de se traçarem estratégias para superá-la, são 
muitas as vozes que se levantam propondo caminhos diversos e muitas soluções são asseveradas. A perquirição é complexa e não se esgota, por certo, numa ou noutra solução, considerando que diversas são as concausas que interferem no sistema, devendo crescer a consciência de que nenhuma ação e saber isolados são capazes de dar resposta efetiva ao problema. Se não faltam remédios, o mesmo não se diga quanto à disposição de aglutiná-los de forma racional, eficiente e, sobretudo, a partir da participação cívica. O estudo aponta como resistência passiva às propostas de mudança a censura judicial desenvolvida sob forte inspiração de aplicação de velhos paradigmas às novas realidades, mantendo os gestores do Judiciário frente a estas uma postura conservadora, orientada pela obsoleta concepção de ser o Estado o único detentor do conhecimento necessário para gerir as atividades que lhe são inerentes. Tal postura funciona como bloqueio à exploração das propostas de novos modelos relacionais, como o da governança, assim como de um modelo de gestão da qualidade e, como resultado do emprego deste, de ações políticas permanentes, como a de fomento aos meios complementares de acesso à justiça, que poderiam estar sendo empregados para a obtenção de uma maior eficiência da administração judiciária. Tudo a partir do indispensável aproveitamento da expertise de agentes qualificados ao enriquecimento do processo de decisão e de uma alta cúpula devidamente preparada para a elaboração de estratégias que levem em conta não só o aspecto quantitativo, mas a qualidade do serviço prestado à sociedade.

\section{REFERÊNCIAS}

BARROSO, Luís Roberto. Curso de Direito Constitucional Contemporâneo: os conceitos fundamentais e a construção do novo modelo. São Paulo: Saraiva, 2009.

. O Direito Constitucional e a efetividade de suas normas: limites e possibilidades da constituição brasileira. Rio de Janeiro: Renovar, 2006.

BOBBIO, Norberto. A era dos direitos. 19. reimp. Tradução de Carlos Nelson Coutinho. Rio de Janeiro: Campus, 1992.

.Teoria geral da política: a filosofia política e as lições dos clássicos. Tradução de Daniela Beccaccia Versiani. 9. reimp. Rio de Janeiro: Elsevier, 2000.

BOURGON, Jocelyn. New Governance and Public Administration: Towards a Dynamic Syntesis. Disponível em: http://jocelynebourgon.com/documents/Governance\%20Paper- Canberra\%20_Feb_16_v21\%20_PMilley\%20Edits_.pdf. Acessado em: 15.05.2013.

BUENO, Marcos. Gestão pela Qualidade Total: uma estratégia administrativa. Um tributo ao mestre do controle da qualidade total, Kaoru Ishikawa. Disponível em: http://www.psicologia.pt/artigos/textos/A0210.pdf. Acessado em: 14.05.2013.

CALMON, Eliana. CNJ e democratização do Poder Judiciário. Revista Interesse 
Nacional, de 03/01/2012, pp. 1-13. Disponível em: http://interessenacional.uol.com. br/2012/01/cnj-e-democratizacao-do-poder-judiciario. Acessado em: 15.05.2013.

CAMPOS, Vicente Falconi. TQC: Controle da Qualidade Total (no estilo japonês). Belo Horizonte, MG: Bloch Editora, 1992.

CARAVANTES, Geraldo R.; CARAVANTES C.; BIJUR, W. Administração e Qualidade: a superação dos desafios. São Paulo: Makron Books, 1997.

CNJ, Relatório em Números 2011, publicado em outubro/2012. Disponível em: http://www.cnj.jus.br/programas-de-a-a-z/eficiencia-modernizacao-e-transparencia/ pj-justica-em-numeros/relatorios. Acessado em: 11.08.2013.

Declaração Universal dos Direitos do Homem. Disponível em: http://portal.mj.gov. br/sedh/ct/legis_intern/ddh_bib_inter_universal.htm. Acessado em: 13.05.2013.

FGV, Índice de Confiança na Justiça - ICJ- Brasil. $4^{\circ}$ trimestre de 2012. Disponível em: http://bibliotecadigital.fgv.br/dspace/bitstream/handle/10438/10754/Relatorio_ ICJBrasil_4TRI_2012.pdf? sequence=1. Acessado em: 12.08.2013.

GAZ, Ricardo; Santana, Talita Gomes de. Unidos pela qualidade. Rio de Janeiro: COP Editora Ltda., 2004 (Artigo publicado na Revista Tendências do Trabalho, edição $\left.n^{\circ} 355\right)$.

GORDILHO, Austin A. La administración paralela. 3. reimp. Madrid: Cuadernos Civistas, 2001.

GRECO, Leonardo. Garantias Fundamentais do Processo: o processo justo. Disponível em: http://www.mundojuridico.adv.br. Acessado em: 13.05.2013.

JURAN, Joseph M.; GRYNA, Frank M. Controle da qualidade. São Paulo: Makron, McGraw-Hill, 1991.

MACIEIRA, Maria Elisa; MARANHÃO Mauriti. Como implementar a gestão em unidades judiciárias. Rio de Janeiro: FGV, 2010.

MANCUSO, Rodolfo de Camargo. A resolução dos conflitos e a função judicial no Contemporâneo Estado de Direito (nota introdutória). Disponível em: http://www. processoscoletivos.net/doutrina/19-volume-1-numero-2-trimestre-01-01-2010-a31-03-2010/93-a-resolucao-dos-conflitos-e-a-funcao-judicial-no-contemporaneo -estado-de-direito-nota-introdutoria. Acessado em: 15.05.2013.

MAUS, Ingborg. O Judiciário como superego da sociedade. Rio de Janeiro: Lumen Juris, 2010.

MORIN, Edgard. Introdução ao pensamento complexo. 4. ed. Porto Alegre: Sulina, 2011.

NASCIMENTO, Rogério José Bento Soares do. Reforma de sistemas de gestão na 
área de Justiça. In Política de Gestão Pública Integrada. Bayma de Oliveira, Fátima (org). Rio de Janeiro: FGV, 2008.

PASOLD, Cesar Luiz. Função Social do Estado Contemporâneo. 3. ed. Santa Catarina: Editora Diploma Legal, 2007.

PONCIANO, Vera Lúcia Feil. Morosidade da Justiça: Crise do Judiciário ou crise do Estado? O Estado do Paraná. Edição de 10/07/2008.

SADEK, Maria Teresa; ARANTES, Rogério Bastos. A crise do judiciário e a visão dos juizes. Revista USP, nº 21. São Paulo: USP, mar-abr. 1994.

SEN, Amartya. A ideia de justiça. São Paulo: Companhia das Letras, 2011.

SILVA, José Afonso da. Curso de Direito Constitucional Positivo. 35. ed. São Paulo: Malheiros, 2012.

THE WORLD BANK. Governance: the World's Bank Experience (Development in Pratice), 1992, p. 14. Disponível em: http://www-wds.worldbank.org/external/ default/WDSContentServer/WDSP/IB/1994/05/01/000009265_3970716142854/ Rendered/PDF/multi0page.pdf. Acessado em: 12.10.2012.

WOLKMER, Antonio Carlos. História do Direito no Brasil. Rio de Janeiro: Forense, 2010. 